\title{
Enhancing Strawberry Productivity through Bee Pollination
}

\author{
Asiko Grace*, Oketch Jane, Mochorwa Jared, Nzano Patricia, Momanyi Dinah, Okecha Teresa, \\ Okinyi Blaise, Koech Christine, Yego Ruth, Palla David
}

Ministry of Agriculture, Livestock and Fisheries, State Department of Livestock, National Beekeeping Institute, Nairobi, Kenya

Copyright $\bigcirc 2017$ by authors, all rights reserved. Authors agree that this article remains permanently open access under the terms of the Creative Commons Attribution License 4.0 International License

\begin{abstract}
Bees play a vital role in strawberry pollination, for fruit quality and increased productivity. Greenhouse experiments were conducted at the National Beekeeping Institute, in collaboration with EU-AU Sponsored ICIPE Bee Health Project. Using honeybee pollinators increased super quality fruits ( $84 \%$ total). Harvested industry fruits were absent in the open field plants, outside the greenhouse, with multi-pollinators. These, however, greatly reduced in the harvested fruits, inside the greenhouse ( $4.3 \%$ total), with the honeybee as the sole pollinator, demonstrating the superiority of the latter in enhancing strawberry productivity through pollination.
\end{abstract}

Keywords Bees, Pollination, Fruit Quality, Increased Productivity

\section{Introduction}

Pollination is a vital biological process for improved quantity and quality crop and fruit yields [1-3]. A large number of fruits and vegetables such as: Strawberries, Bananas, Melon, Citrus, Avocado, Cucumber, are bee-pollinated. Valuation of honey bee pollination to crop yields reveal \$US 238.9 Billion worldwide [4]. Many pollinating agents are involved, especially insects [5]. Insect pollinators play a complementary role in obtaining maximum fruit-set [6]. Stingless bees and Solitary bees are equally becoming recognized as essential and specialized pollinators, other than the honey bee [7-9].

\section{Materials and Methods}

The experiment was conducted in a greenhouse, $8 \times 24$ Meter in size. Only half the Proportion was used, 8x12 Meter. It was Purchased by ICIPE from Amiran Company and Issued to the National Beekeeping Institute, as part of the Bee health collaboration Project, sponsored by African
Union and European Union.

- Strawberry was propagated from older cultivars and 230 young splits planted both inside and outside the greenhouse. The study plants were clearly labeled, Figure1.

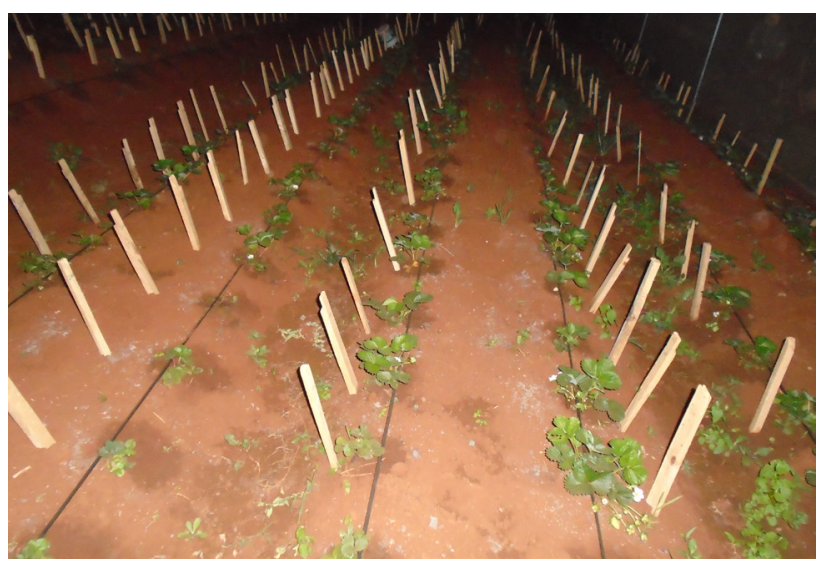

Figure 1. Clearly labeled young strawberry plants, propagated from splits of older plants

- Drip Irrigation was Installed and Applied Every Day, Figure 2.

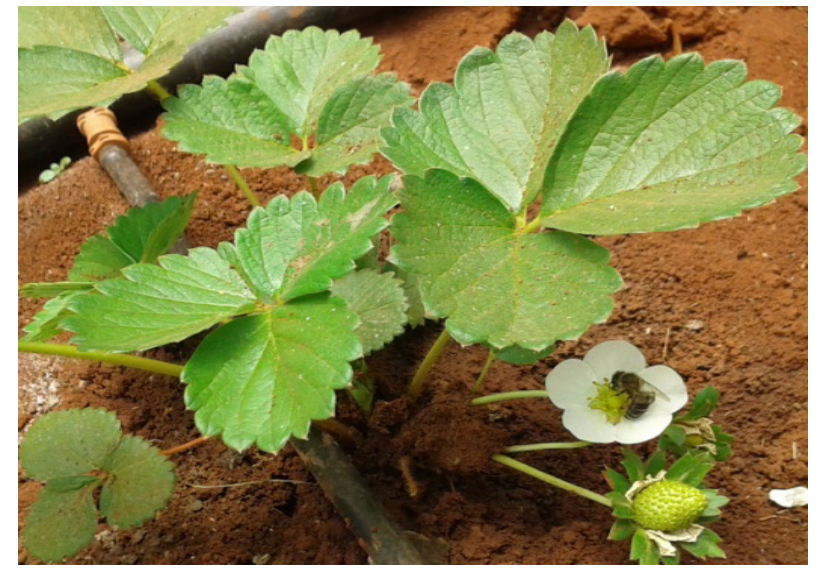

Figure 2. Drip irrigation 
- A pollinator species, honey bees, Apis mellifera scutellata was placed inside the greenhouse for the pollination service

- Ripe fruits were harvested, measure and weighed, Figures. 3- 5

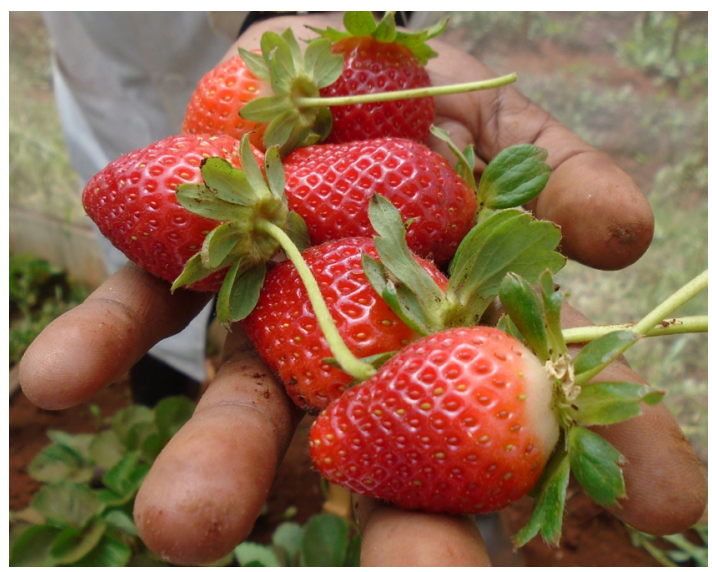

Figure 3. Rotunda strawberry cultivar, super Quality

- Fruit Size Measurement Using a Ruler, in Millimeters, Figure 4

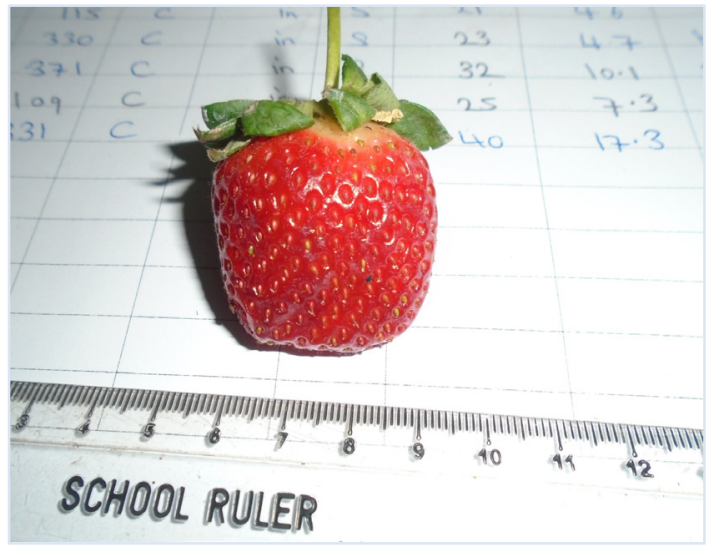

Figure 4. Fruit size measurement

- Weighing a Strawberry Fruit, figure 5

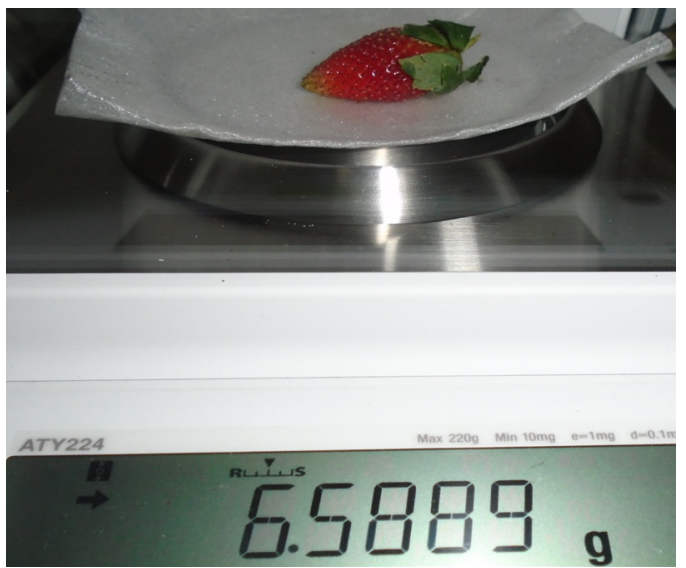

Figure 5. Fruit weight
- Pollination Deficiency, Figures. 6 and 11

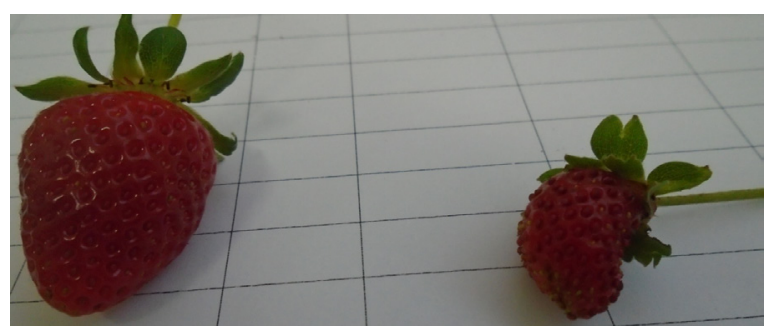

Figure 6. a, effectively pollinated and b, pollination deficient strawberry

\section{Results}

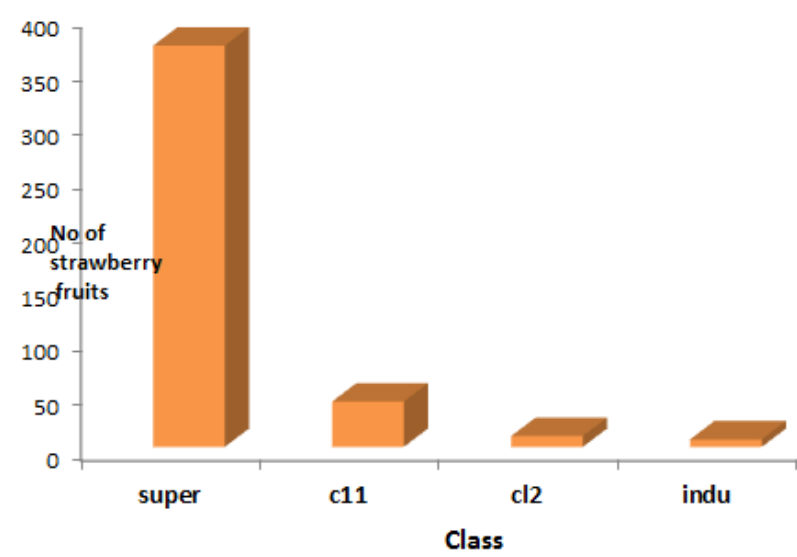

Figure 7. Strawberry pollination in a greenhouse

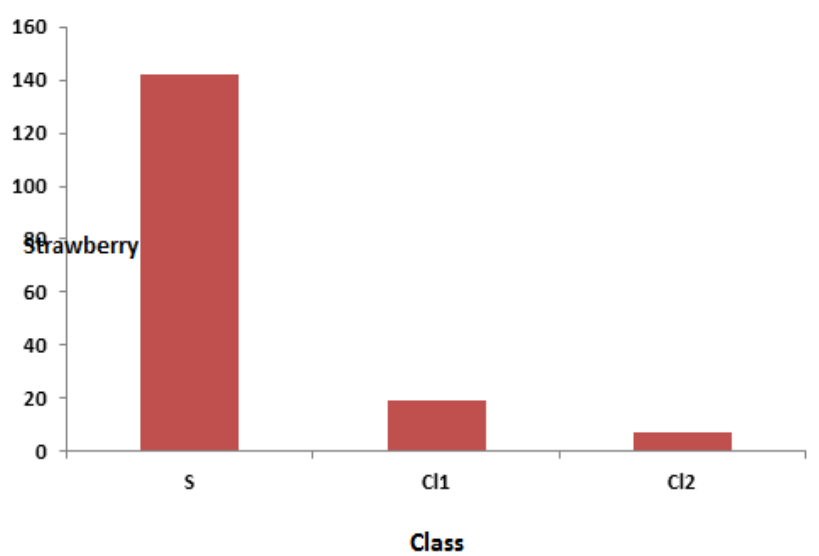

Figure 8. Strawberry pollination outside a greenhouse

Pearson Chi-square test for Association between pollinator and class quality

$$
\left(\chi^{2}=22.71: \text { d.f. } 3 ; p=0.007\right)
$$

\begin{tabular}{|c|c|c|c|}
\hline [1] Class & [2] IN & [3] OUT & [4] Grand Total \\
\hline [5] CL.I & {$[6] 9.35 \%$} & {$[7] 13.66 \%$} & {$[8] 10.03 \%$} \\
\hline [9] CL.II & {$[10] 2.67 \%$} & {$[11] 6.01 \%$} & {$[12] 3.20 \%$} \\
\hline [13] INDU & {$[14] 4.32 \%$} & {$[15] 0.00 \%$} & {$[16] 3.63 \%$} \\
\hline$[17]$ SUPER & {$[18] 83.66 \%$} & {$[19] 80.33 \%$} & {$[20] 83.13 \%$} \\
\hline
\end{tabular}




\section{Average strawberry fruit size by location $(p<0.001, t=5.42, d . f=1154)$}

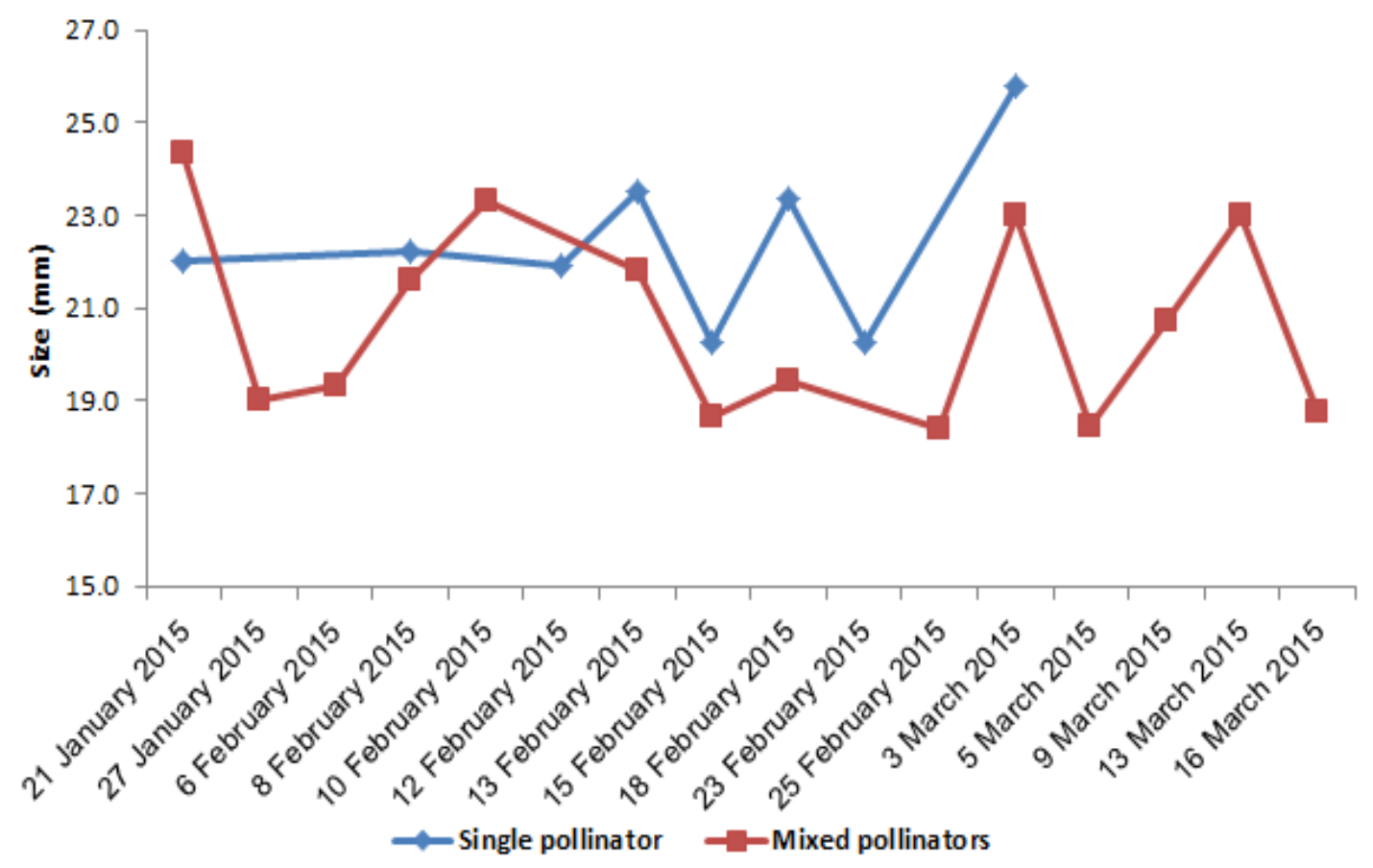

Figure 9. Average strawberry size, inside and outside the greenhouse

Average size in $\mathrm{mm}$

$(\mathrm{p}<0.001, \mathrm{t}=5.42, \mathrm{df}=\mathbf{1 1 5 4})$

\begin{tabular}{|c|c|c|c|}
\hline [21] Row Labels & [22] Single pollinator & [23] Mixed pollinators & [24] Grand Total \\
\hline [25] 21 January 2015 & {$[26] 22.0$} & [27] 24.3 & {$[28] 22.2$} \\
\hline [29] 27 January 2015 & {$[30]$} & [31] 19.0 & [32] 19.0 \\
\hline [33] 6 February 2015 & {$[34]$} & [35] 19.3 & [36] 19.3 \\
\hline [37] 8 February 2015 & [38] 22.2 & [39] 21.6 & [40] 22.2 \\
\hline [41] 10 February 2015 & {$[42]$} & [43] 23.3 & [44] 23.3 \\
\hline [45] 12 February 2015 & [46] 21.9 & {$[47]$} & [48] 21.9 \\
\hline [49] 13 February 2015 & {$[50] 23.5$} & [51] 21.8 & [52] 23.4 \\
\hline [53] 15 February 2015 & [54] 20.3 & [55] 18.7 & {$[56] 20.0$} \\
\hline [57] 18 February 2015 & {$[58] 23.4$} & [59] 19.4 & {$[60] 23.2$} \\
\hline [61] 23 February 2015 & [62] 20.3 & {$[63]$} & [64] 20.3 \\
\hline [65] 25 February 2015 & {$[66]$} & [67] 18.4 & [68] 18.4 \\
\hline [69] 3 March 2015 & [70] 25.8 & [71] 23.0 & {$[72] 25.5$} \\
\hline [73] 5 March 2015 & {$[74]$} & {$[75] 18.5$} & [76] 18.5 \\
\hline [77] 9 March 2015 & {$[78]$} & [79] 20.7 & {$[80] 20.7$} \\
\hline [81] 13 March 2015 & {$[82]$} & {$[83] 23.0$} & {$[84] 23.0$} \\
\hline [85] 16 March 2015 & {$[86]$} & [87] 18.8 & {$[88] 18.8$} \\
\hline [89] Grand Total & [90] 22.7 & [91] 20.4 & [92] 22.4 \\
\hline
\end{tabular}




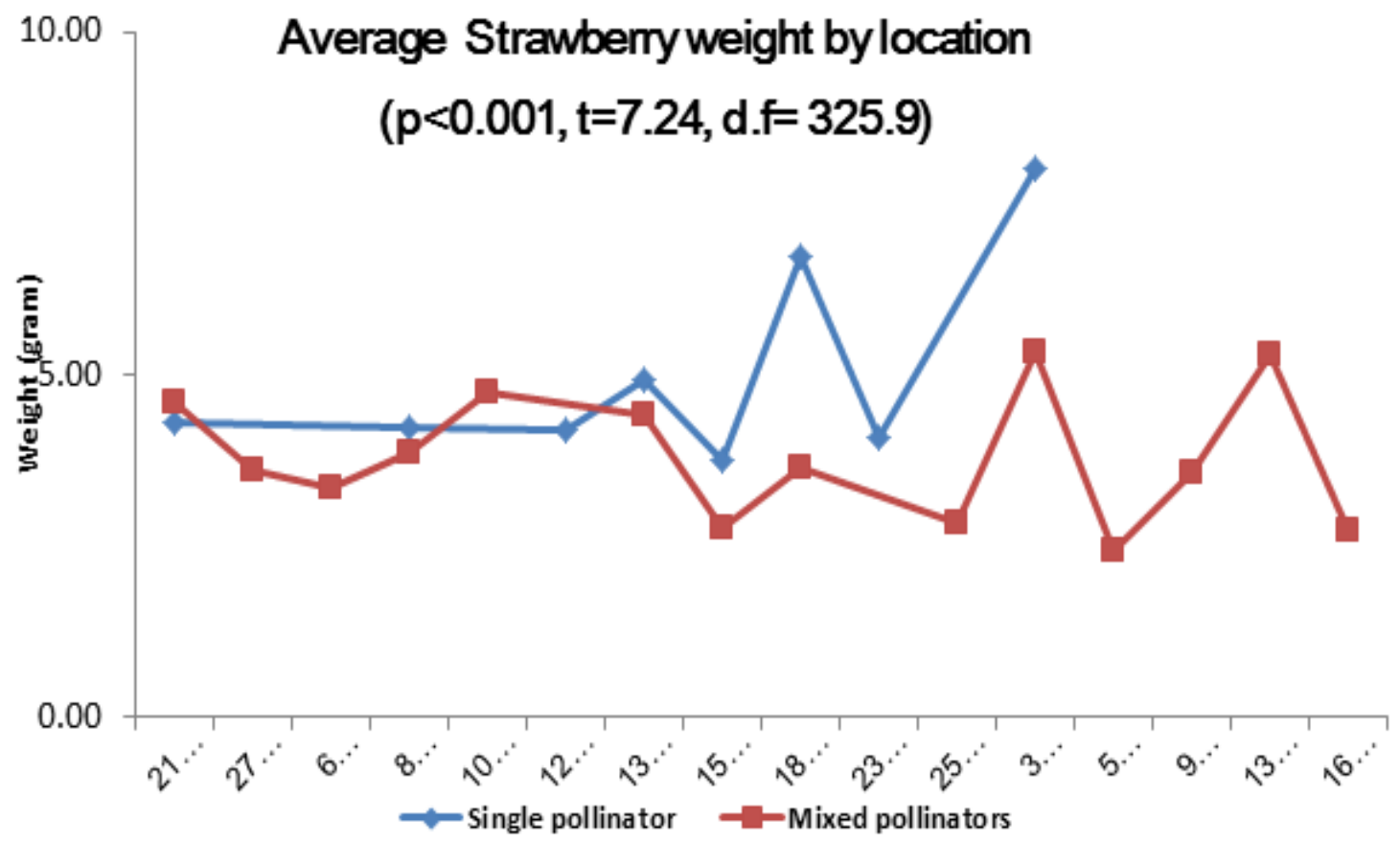

Figure 10. Average strawberry weight, inside and outside the greenhouse

Average mass in gms

$\mathbf{P}<0.001, \mathrm{t}=7.24, \mathrm{df}=325.9$

\begin{tabular}{|l|l|l|l|}
\hline [93] Row Labels & {$[94]$ Single pollinator } & {$[95]$ Mixed pollinators } & {$[96]$ Grand Total } \\
\hline$[97] 21$ January 2015 & {$[98] 4.29$} & {$[99] 4.60$} & {$[100] 4.31$} \\
\hline$[101] 27$ January 2015 & {$[102]$} & {$[103] 3.59$} & {$[104] 3.59$} \\
\hline$[105]$ F February 2015 & {$[106]$} & {$[107] 3.36$} & {$[108] 3.36$} \\
\hline$[109]$ F February 2015 & {$[110] 4.23$} & {$[111] 3.86$} & {$[112] 4.18$} \\
\hline$[113]$ 10 February 2015 & {$[114]$} & {$[115] 4.74$} & {$[116] 4.74$} \\
\hline$[117]$ 12 February 2015 & {$[118] 4.21$} & {$[119]$} & {$[124] 4.88$} \\
\hline$[121]$ 13 February 2015 & {$[122] 4.94$} & {$[123] 4.39$} & {$[128] 3.60$} \\
\hline$[125] 15$ February 2015 & {$[126] 3.75$} & {$[127] 2.76$} & {$[132] 6.56$} \\
\hline$[129]$ 18 February 2015 & {$[130] 6.73$} & {$[131] 3.62$} & {$[136] 4.10$} \\
\hline$[133] 23$ February 2015 & {$[134] 4.10$} & {$[135]$} & {$[140] 2.84$} \\
\hline$[137] 25$ February 2015 & {$[138]$} & {$[139] 2.84$} & {$[144] 7.77$} \\
\hline$[141] 3$ March 2015 & {$[142] 8.01$} & {$[143] 5.34$} & {$[148] 2.43$} \\
\hline$[145] 5$ March 2015 & {$[146]$} & {$[147] 2.43$} & {$[152] 3.57$} \\
\hline$[149]$ March 2015 & {$[150]$} & {$[151] 3.57$} & {$[156] 5.29$} \\
\hline$[153] 13$ March 2015 & {$[154]$} & {$[155] 5.29$} & {$[160] 2.73$} \\
\hline$[157] 16$ March 2015 & {$[158]$} & {$[159] 2.73$} & {$[164] 5.097413194$} \\
\hline$[161]$ Grand Total & {$[162] 5.356449948$} & {$[163] 3.72579235$} & \\
\hline
\end{tabular}

\section{Discussion}

Results indicate a significant increase in strawberry quality, $(\mathbf{p}<\mathbf{0 . 0 0 1}, \mathbf{F}=\mathbf{1 . 8 7}$, $\mathbf{d . f}=\mathbf{1 8 2}$ on $\mathbf{9 6 8})$, to super class (84\%), as a result of honeybee pollination and reduced mal-formed industry quality, in the greenhouse, Figs. $6 \& 11$. The increase was replicated on the outside field plot, with mixed Pollinators (bees, butterflies, birds and predators: Baboons, people), where $80 \%$ super quality fruits were recorded, Figs. 7-10. The size and mass of strawberry fruits, too increased significantly, $\mathrm{P}<0.001, \mathrm{t}=5.42$, d. $\mathrm{f}=1154$ and $\mathrm{P}<0.001, \mathrm{t}=7.24$, d. $\mathrm{f}=325$, respectively. The mean size of the fruit was 22.7 and $20.4 \mathrm{~mm}$, for the greenhouse plants and outside field plot plants in that order, compared to 5.4 and 3.7 g for mass, respectively.

\section{Conclusions}

Incorporate appropriate bee pollinator species in the 
greenhouse, at the recommended colony density, Table 1, for optimum returns at niche markets and sustainable premium strawberry production. The honeybee, Apis mellifera scutellata, was an excellent strawberry pollinator, accounting for $84 \%$ of super quality fruits harvested in the greenhouse, Fig. 4, 5 \&11, with a significant increase in quality and quantity. Size and mass in strawberry may interchangeably be used to qualify Productivity. The greenhouse acted as a shield to prevent strawberry predators, hence contributing to sustainable fruit productivity.

\section{Appendix I}

Table 1. Pollination requirements for selected fruits/crops, based on honeybee colonies, FAO, 2005

\begin{tabular}{|c|c|c|}
\hline $\mathrm{S} / \mathrm{N}$ & Fruit/crop & No. of colonies/hectare \\
\hline 1 & Strawberry & $0.6-5$ \\
\hline 2 & Apples & $1-5$ \\
\hline 3 & Pears & $1-3$ \\
\hline 4 & Plums & $2.5-5$ \\
\hline 5 & Cherries (sour) & $1.3-3$ \\
\hline 6 & Cherries (sweet) & $2.5-7.5$ \\
\hline 7 & Avocado & $2-12.5$ \\
\hline 8 & Almond & $0.5-7.5$ \\
\hline 9 & Melon & $0.5-5$ \\
\hline 10 & Water melon & $0.3-10$ \\
\hline 11 & Cucumber & $7.5-12$ \\
\hline 12 & Kiwi fruit & $1-4$ \\
\hline 13 & Sunflower & \\
\hline
\end{tabular}

\section{Appendix II: The Greenery International Quality Description of Strawberry}

"The Greenery International" quality description
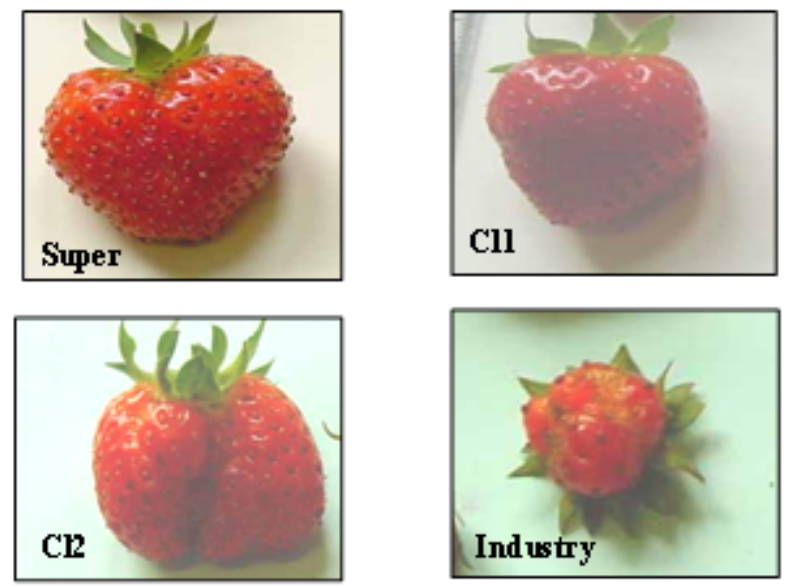

Figure 11. International strawberry quality description

\section{Acknowledgements}

1. ICIPE, Particularly Prof. Raina and Dr. Kiatoko, for incorporating the National Beekeeping Institute in the AU/EU Sponsored Bee Health Program.

2. Ministry of Agriculture, State Department of Livestock, through the Director, Mr. Julius Kiptarus and the Principle Secretaries, Prof. Segor and Prof. Andrew Tuimur.

3. Staff, National Beekeeping Institute, especially, Kennedy Wabule, Jacqueline Onege and Agnes Nyaribo, who assisted in data taking and typing, respectively.

4. Egerton University, for organizing the Research conference.

\section{REFERENCES}

[1] a. Eva Crane and Penelope Walker, 1984. Pollination Directory for world crops. IBRA, London

[2] b. Crane E, 1985. World Perspectives in Apiculture.

[3] Bradbear Nicola, 2009. Beekeeping and Sustainable Livelihoods. Second Edition, FAO-Rome

[4] Asiko G A, 2012. Pollination of Strawberry by Stingless bees and Honeybee for Improved Fruit Quality. phd Thesis

[5] Gallai Nicola and Bernard Vaissiere, 2009. Pollination Services for Sustainable Agriculture, guidelines For the economic valuation of Pollination Services at a National Scale. FAO, Rome.

[6] Roubik D.W, 1995. Pollination of cultivated plants in the tropics, FAO Agricultural bulletin. No.118, Rome, Italy. $196 \mathrm{pp}$.

[7] Free J.B, 1968a. The pollination of strawberries by honeybees. Journ. of hort. Scie. 43. Bulletin E-2985. Department of Entomology, Michigan State University.

[8] Jaycox E.R, 1979. The Pollination of strawberries. American bee Journ Vol. 113(8) 575: 573-593.

[9] Rufus Isaacs and Juliana Tuell, may 2007. Conserving Native Bees on farmland. Extension Bulletin E-2985. Department of Entomology, Michigan State University.

[10] Harmon Heather, 2007. Farming for Native Bees. DDA, Plant Industries leaflet. Heard T.A, 1999. The role of stingless bees in crop pollination. Annual Review Entomology 44: 183-206.

[11] Southwick E.E and Southwick L. Jr, 1992. Estimating the economic value of honeybees (Hymenoptera: Apidae) as Agricultural Pollinators in the United States. J. Eco. Entomol. 85: 621-633.

[12] FAO, 2005. Global Pollination Project Proposal. Rome, Italy 